\title{
Numerical approaches in idealizing mass of fluid in tank for ship vibration analysis
}

\author{
Jung Hoon Byeon ${ }^{1}$, Hyun Jin $\mathrm{Cho}^{1}$, Seung Jun Baek $^{2}$, Aditya Rio Prabowo ${ }^{1}$, Dong Myung \\ $\mathrm{Bae}^{2}$, and Jung Min Sohn ${ }^{1,2^{*}}$ \\ ${ }^{1}$ Pukyong National University, Marine Convergence Design, 48513 Busan, Korea \\ ${ }^{2}$ Pukyong National University, Naval Architecture and Marine Systems Eng., 48513 Busan, Korea
}

\begin{abstract}
Vibration analysis is a crucial process in ship design to guarantee crew's comfortability and to save operating costs by predicting problematical resonance in advance. This study focuses on idealizing fluid mass in tanks by positioning point mass element and quad elements inside the tanks. Also, the added mass effect induced sea water surrounding a ship was included in the present study. The natural frequency obtained from free and forced ship vibration analysis were compared and assessed in the manner of ISO regulation. Finally, it was concluded that the quad element was more adequate to idealize fluid entities in tanks since it was difficult in arranging point mass elements at each grid points properly.
\end{abstract}

\section{Introduction}

Ship design is a sustainable process which each stage correlates each other. A design assessment should be conducted to achieve the optimum level and to satisfy demands of the ship owner for the purpose of operational costs. Ship vibration analysis is one of assessment categories to reduce additional expenses before sea trial by solving resonance problems which is related to fatigue damage which has potential to cause a remarkable financial loss.

A ship is accelerated in the ocean, sea water surrounding the ship simultaneously has to be accelerated. This is called an inertial effect known as added mass effect which has a tendency to make natural frequencies decrease [1]. In the early 20th century, added mass used to be approximated through using a submerged circular cylinder [2]. After computational performances had been developed, more accurate methodologies were calculated by using finite element method.

The virtual mass method in NASTRAN using fluid-structure interaction has been used as an adequate technique to consider an added mass effect caused by sea water [3]. However, it is not appropriate to analyse the situation which hydrodynamic forces are applied on inner and outer sides simultaneously because this method is proper to solve a simply connected domain [4]. However, ship vibration analysis should reflect the contact with a liquid at both sides to take into account fluid entities in tanks, e.g. fresh water, heavy fuel oil and lubricating oil. Hence, additional methodologies are needed: point mass elements and/or quad elements.

\footnotetext{
*Corresponding author: jminz@pknu.ac.kr
} 
This study investigates the global ship vibration of a 1500-ton fishery research vessel using finite element method and summarizes the dynamic structural response depending on methodologies. Added mass induced from sea water was calculated by the virtual mass method which utilizes MFLUID card in NASTRAN. Fluid in tanks was dealt with additional two methods to remedy a mentioned disadvantage of the virtual mass method. Also, free and forced vibration analysis were conducted to compare two methodologies and its results were evaluated based on the Guidance Note and ISO standards [5-6].

\section{Methods for considering added mass}

An added mass matrix is obtained by using MFLUID card in NASTRAN [4] which solves Laplace's equation by distributing a set of sources over the outer boundary. In this paper, MFLUID card was used to consider the added mass effect induced by the sea water contacted with the outer shell plates. All flow is assumed inviscid and irrotational. The velocity $\boldsymbol{u}_{L}$ at any point is defined as follows:

$$
\dot{u}_{i}=\sum_{j} \int_{A_{j}} \frac{\sigma_{j} \boldsymbol{e}_{i j}}{\left|\boldsymbol{r}_{i}-\boldsymbol{r}_{j}\right|^{2}} d A_{j}
$$

where $\boldsymbol{\sigma}_{\mathrm{i}}$ is the value of a point source of fluid (units are volume flow rate per area) located at location $\mathbf{r}_{\mathrm{i}}$ and the point source is assumed acting over an area $\mathbf{A}_{\mathrm{j}}$ while $\mathbf{e}_{\mathrm{ij}}$ is the unit vector in the direction from point $j$ to point $i$. The pressure, $\mathbf{p}_{i}$, at any point is following:

$$
\dot{\boldsymbol{p}}_{i}=\sum_{j} \int_{A_{j}} \frac{\rho \dot{\sigma}_{j} \boldsymbol{e}_{i j}}{\left|\boldsymbol{r}_{i}-\boldsymbol{r}_{j}\right|^{2}} d A_{j}
$$

where $\rho$ is density.

After that two matrices, $[\chi]$ and $[\Lambda]$, can be obtained by integrating (1) and (2) equations over the surfaces adjacent to fluid,

$$
\begin{aligned}
& \{\dot{u}\}=[\chi][\sigma] \\
& \{F\}=[\Lambda]\{\dot{\sigma}\}
\end{aligned}
$$

where $\mathrm{F}$ are the forces converted from the pressures at the grid points. Then, if $[\chi]$ is not singular, an added mass matrix, $\left[\mathrm{M}_{\mathrm{f}}\right]$, is derived by combing (3) and (4) as follows:

$$
\{F\}=[\Lambda]\{\chi\}^{-1}\{\ddot{u}\}=\left[M_{f}\right]\{\ddot{u}\}
$$

Then, an advanced added mass matrix when $[\chi]$ is singular or nearly singular is obained by introducing a set of Lagrange multipliers [4] as follows:

$$
\{F\}=\left[\begin{array}{ll}
\Lambda \chi^{T} & \Lambda_{2}
\end{array}\right]\left[\begin{array}{cc}
\chi \chi^{T} & \chi_{2} \\
\chi_{2}^{T} & 0
\end{array}\right]^{-1}\left\{\begin{array}{l}
\ddot{u} \\
0
\end{array}\right\}=\left[M_{f}\right]\{\ddot{u}\}
$$

The added mass matrix is combined with the ordinary mass matrix, $\left[\mathrm{M}_{\mathrm{s}}\right]$, in the characteristic equation to solve an eigenvalue problem as follows:

$$
\operatorname{det}\left([K]-\omega^{2}\left(\left[M_{s}\right]+\left[M_{f}\right]\right)\right)=0
$$

where $\omega$ is natural freequency which is calculated by Lanczos method [7]. 


\section{A simple cargo tank}

The fluid entities in the tanks can be modeled by two kinds of methods: point mass elements and quad elements. The former one is that weight of the fluid entities is equally distributed on every node point. The other is to model additional quad elements at the same location as the the fluent entities. It is important to generate quad elements which has neligible stiffness. Fig. 1 shows the effect of fluid stiffness on the results. In the results, it was verified that stiffness of quad elements for fluid should be a million times smaller than the stiffness of structural elemenets.

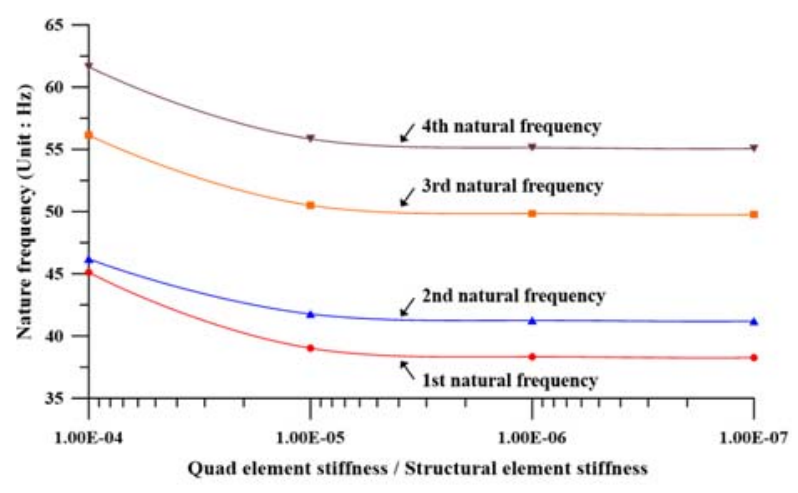

Fig. 1 Influence of stiffness.

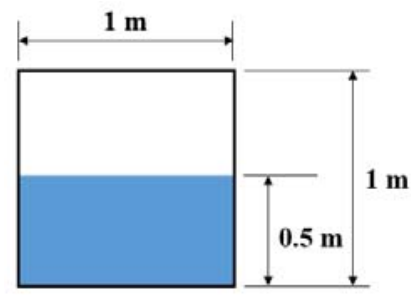

Fig. 2. Principal dimension of half-filled tanks.

It is easily expected that they show the identical results. However, the results varied depending on mass arrangement. In the case of quad elements, mass is automatically calculated by considering the area, and the identical mass is placed on each node which composes an element. If one element is adjacent to the other elements, the mass of adjacent node is overlapped. Therefore, the mass of node in quad elements is determined depending on the area of the element, the number of node in one element and the number of contiguous elements. However, the mass of nodes using point mass does not consider those items, every node are the same. Mass on one node is calculated that the total mass is divided by the total number of node.

In regard to this problem, the tank with half-filled water were used as a numerical example, as shown in Fig. 2. Density of tank and water were given as $\rho_{\mathrm{t}}=7850 \mathrm{~kg} / \mathrm{m}^{2}$ and $\rho_{\mathrm{w}}=1000 \mathrm{~kg} / \mathrm{m}^{2}$. Point mass method is divided into two parts : one is equally distributed, the other is well arranged by considering the mentioned items. Table 1 shows comparisons of methods. A little gap is shown between uniformly posed point mass and quad element. Otherwise, the same result is obtained between well-arraged point and quad element. Therefore, it is verified that mass arrangement should be considered the area of structural elements. It is not easy to consider various shaped element as the structure becomes more complicated. 
Table 1. Influence of mass arrangement (Unit: Hz).

\begin{tabular}{|c|c|c|c|c|c|c|}
\hline \multicolumn{2}{|c|}{ Method } & 1st & 2nd & 3rd & 4th & 5th \\
\hline \multirow{2}{*}{$\begin{array}{c}\text { Point } \\
\text { element }\end{array}$} & Uniformly posed & 38.684 & 39.928 & 48.585 & 53.893 & 69.440 \\
\cline { 2 - 7 } & Well-arranged & 38.250 & 41.190 & 49.762 & 55.049 & 69.397 \\
\hline \multicolumn{2}{|c|}{ Quad element } & 38.250 & 41.191 & 49.762 & 55.049 & 69.397 \\
\hline
\end{tabular}

\section{Ship vibration analysis}

A 1500-ton fishery research vessel was used for the target for ship vibration analysis. Principal dimensions and the main information are summarized in Table 2. A half of finite element model is shown in Fig. 3, and weight of the fluide entities is modelled like as Fig. 4. In the case of point mass method, mass of fluid entities was uniformly distributed in each node to avoid expending time.

Loading conditions for vibration analysis were normal ballast arrival condition and scantling departure condition. Details of conditions are specified in Table 3.

Table 2. Principal dimensions of the target vessel.

\begin{tabular}{|c|c|}
\hline Item & Description \\
\hline Type of ship & Fishery research vessel \\
\hline Displacement & 1500.0 Ton \\
\hline Length over all & $75.7 \mathrm{~m}$ \\
\hline Length between perpendicular & $64.5 \mathrm{~m}$ \\
\hline Breadth (Moulded) & $13.8 \mathrm{~m}$ \\
\hline Depth (Moulded) & $7.4 \mathrm{~m}$ \\
\hline Draft (Scantling) & $4.8 \mathrm{~m}$ \\
\hline Number of blades & $4 / 5 \mathrm{EA}$ (front/aft) \\
\hline 1st harmonic frequency & $13.2 / 16.4 \mathrm{~Hz}$ (front/aft) \\
\hline
\end{tabular}

Fig. 3. Finite element model.

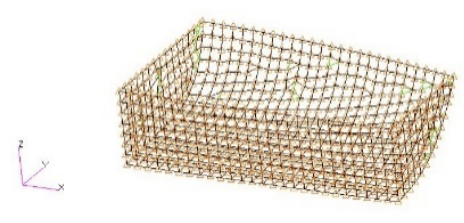

Fig. 4a. Point mass elements.

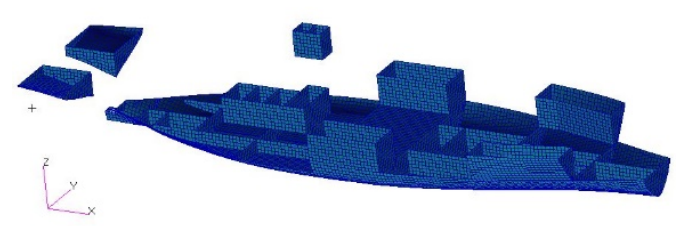

Fig. 4b. Quad elements. 
Table 3. Details of conditions.

\begin{tabular}{|c|c|c|}
\hline & Normal ballast arrival & Scantling departure \\
\hline Deadweight & 306.4 Ton & 717.2 Ton \\
\hline Lightweight & 1830.0 Ton & 1830.0 Ton \\
\hline Displacement & 2136.4 Ton & 2547.2 Ton \\
\hline Draft F.P. & $3.8 \mathrm{~m}$ & $4.9 \mathrm{~m}$ \\
\hline Draft A.P. & $4.8 \mathrm{~m}$ & $4.9 \mathrm{~m}$ \\
\hline Draft equivalent & $4.4 \mathrm{~m}$ & $4.9 \mathrm{~m}$ \\
\hline
\end{tabular}

Free vibration analysis is conducted to avoid problomatical resonance with major excitational sources such as propellers and the main engine. In this study, vibration analysises were conducted by NASTRAN [4]. Table 4 represents the results of free vibration analysis. The possibility of resonance induced by the propellers was significantly low since the natural frequencies of global modes was notably lower than 1 st harmonic frequencies of prepellers. On the other hand, the difference of natural frequencies between two methods was under 0.06 percent. It is marginal because tank weight is a small portion of the whole ship.

Table 4. Natural frequency obtained from free vibration analysis (Unit: $\mathrm{Hz}$ ).

\begin{tabular}{|c|c|c|c|c|c|c|}
\hline \multirow{2}{*}{ Order } & \multicolumn{2}{|c|}{ Normal ballast arrival condition } & \multicolumn{3}{c|}{ Scantling departure condition } \\
\cline { 2 - 7 } & Point & Quad & Err. (\%) & Point & Quad & Err. (\%) \\
\hline Ver. 2-Node & 3.1639 & 3.1638 & 0.0032 & 2.9919 & 2.9932 & 0.0434 \\
\hline Ver. 3-Node & 5.6129 & 5.6142 & 0.0232 & 5.3474 & 5.3501 & 0.0505 \\
\hline Ver. 4-Node & 8.0029 & 7.9986 & 0.0538 & 7.5196 & 7.5227 & 0.0412 \\
\hline Hor. 2-Node & 5.4149 & 5.4137 & 0.0222 & 5.1881 & 5.1888 & 0.0135 \\
\hline
\end{tabular}

The ship used in this study is propelled by the electric propulsions known as Azimuth thruster. Since main power is created from generator engines, an axial force conveyed by shaft does not exist. Thus, major excitational sources are both guide forces induced the generator and fluctuation pressure induced by the proppellers. The engine equipped in the target ship does not have any external force or moment. Hence, the engine only induces guide forces such as 4 th and 8th order moments known as $\mathrm{X}$ and H-moments. 4th order moment, given as $20.8 \mathrm{kN} \cdot \mathrm{m}$, was only considered since 8th order moment, given as 3.0 $\mathrm{kN} \cdot \mathrm{m}$, was negligible. Fluctuation pressure induced by the propeller was considered as 4 $\mathrm{kPa}$ which figure is commonly used as an upper limit for special ships. Damping coefficients normally expressed as a percentage of critical damping are applied according to Guidance notes published by Lloyd's Register [5]. Its value linearly increases from 1 percent of critical damping to 3 percent as the frequency rises from $5 \mathrm{~Hz}$ to $20 \mathrm{~Hz}$.

Forced vibration analysis was conducted by the modal superposition method utilizes the results of free vibration analysis of NASTRAN [3]. The values, specified in Table 5 is maximum values on each observation point. The observation points were selected to verify comfortability in the manner of ISO regulation [6]. Root Mean Square(RMS) velocity is principal criteria for assessment as stated by the ISO 6954:2000 which was enhanced in the manner of considering average vibration velocities. All dynamic structural responses by the global modes were satisfied the lower limit for working comfortability of crews in ISO regulation [6], given as $4 \mathrm{~mm} / \mathrm{s}$. The maximum response of funnel top was $6.3655 \mathrm{~mm} / \mathrm{s}$. Its value is lower than the recommended limit, given as $30 \mathrm{~mm} / \mathrm{s}$, to avoid fatigue fracture [5]. 
Moreover, the difference of dynamic responses between point elements and quad elements were within 5 percent. The error is higher than the results of free vibration analysis because these values are reflected in the whole modes of vibration.

Table 5. RMS velocities in both conditions (Unit: $\mathrm{mm} / \mathrm{s}$ ).

\begin{tabular}{|c|c|c|c|c|c|c|c|c|c|c|c|}
\hline \multirow{2}{*}{ Method } & \multirow{2}{*}{ Dir. } & \multicolumn{2}{|c|}{ Propulsion rm } & \multicolumn{2}{c|}{ AFT. end } & \multicolumn{2}{c|}{ Funnel top } & \multicolumn{2}{|c|}{ Eng. control rm } & \multicolumn{2}{c|}{ Wheel house } \\
\cline { 3 - 12 } & & Nor. & Scant. & Nor. & Scant. & Nor. & Scant. & Nor. & Scant. & Nor. & Scant. \\
\hline \multirow{2}{*}{$\begin{array}{c}\text { Point } \\
\text { element }\end{array}$} & V. & 0.899 & 2.844 & 3.306 & 0.946 & 2.206 & 0.867 & 1.876 & 0.494 & 0.683 & 0.217 \\
\cline { 2 - 12 } & L. & 0.054 & 0.153 & 0.518 & 0.185 & 2.377 & 0.608 & 0.414 & 0.135 & 0.235 & 0.127 \\
\cline { 2 - 12 } & T. & 0.409 & 1.550 & 0.789 & 0.228 & 6.367 & 2.658 & 1.019 & 0.273 & 0.627 & 0.153 \\
\hline \multirow{2}{*}{$\begin{array}{l}\text { Quad } \\
\text { element }\end{array}$} & V. & 0.907 & 2.860 & 3.327 & 0.947 & 2.205 & 0.865 & 1.926 & 0.490 & 0.685 & 0.218 \\
\cline { 2 - 12 } & L. & 0.055 & 0.155 & 0.521 & 0.186 & 2.385 & 0.607 & 0.419 & 0.140 & 0.236 & 0.121 \\
\cline { 2 - 11 } & T. & 0.414 & 1.576 & 0.789 & 0.230 & 6.366 & 2.680 & 1.036 & 0.277 & 0.638 & 0.154 \\
\hline \multirow{2}{*}{$\begin{array}{c}\text { Error } \\
(\%)\end{array}$} & V. & 0.845 & 0.549 & 0.634 & 0.116 & 0.045 & 0.173 & 2.591 & 0.789 & 0.263 & 0.368 \\
\cline { 2 - 11 } & L. & 0.552 & 1.033 & 0.538 & 0.542 & 0.319 & 0.066 & 1.169 & 3.402 & 0.424 & 4.341 \\
\cline { 2 - 11 } & T. & 1.346 & 1.637 & 0.063 & 0.877 & 0.024 & 0.801 & 1.631 & 1.427 & 1.740 & 0.786 \\
\hline
\end{tabular}

\section{Conclusion}

The vibration analysis of the fishery research vessel has been conducted to compare point mass elements with quad elements. The difference of natural frequencies was under 0.06 percent. It verifies that domination from uniform distribution of point mass was negligible. However, the maximum error of dynamic structural responses was about 80 times higher than the error of free vibration analysis because errors triggered by uniformly distributed point mass elements were accumulated. Hence, using quad elements is more suitable methodology for ship vibration analysis. Also, not only there was not possibility of resonance problems but also all dynamic responses were acceptable to the IMO regulation.

This study was successfully presented and published with the support from BK21 plus MADEC Human Research Development Group, Republic of Korea. Authors gratefully acknowledged to Korea Maritime Services Company for research fund. This paper has been presented at the 2nd International Joint Conference on Advanced Engineering and Technology, 24-25 August 2017, Bali, Indonesia.

\section{Reference}

1. T.S. Kim, H.N. Rhee, D.B. Yoon, J.H. Park, Analysis of vibration characteristics of submerged tubes using computational fluid structure interaction analysis, The Proc. of Korean Soc. for Noise and Vib. Eng., 684-685 (2013)

2. Lesser, M. B., J. A. Lewis, Scattering of surface waves by a submerged circular cylinder, J. Math. Phys., 6(8), 1231-1243 (1972)

3. S.H. Choi, K.S. Kim, S.W. Son, Analytic and experimental study on vibration characteristics for rectangular tank structure filled with fluid, The J. of Korean Soc. for Noise and Vib. Eng., 12(3), 195-203 (2002)

4. SIEMENS, Advanced dynamic analysis user's guide (2014)

5. Lloyd's Register, Guidance notes general overview of ship structural vibration problems (2015)

6. International Organization for Standardization, ISO 6954: Mechanical vibration guidelines for the measurement, reporting and evaluation of vibration with regard to habitability on passenger and merchant ships (2000)

7. B.W. Kim, J.H. Kyoung, S.Y. Hong, S.K. Cho, I.W. Lee, Investigation of efficiency of starting iteration vectors for calculating natural modes, The J. of Korean Soc. for Noise and Vib. Eng., 15(1), 112-117 (2005) 